\title{
BMJ Open Cultural epidemiology of pandemic influenza in urban and rural Pune, India: a cross-sectional, mixed-methods study
}

\author{
Neisha Sundaram, ${ }^{1,2}$ Christian Schaetti, ${ }^{1,2}$ Vidula Purohit, ${ }^{3}$ Abhay Kudale, ${ }^{3}$ \\ Mitchell G Weiss ${ }^{1,2}$
}

To cite: Sundaram N, Schaetti C, Purohit V, et al. Cultural epidemiology of pandemic influenza in urban and rural Pune, India: a cross-sectional, mixedmethods study. BMJ Open 2014:4:e006350.

doi:10.1136/bmjopen-2014006350

- Prepublication history for this paper is available online. To view these files please visit the journal online (http://dx.doi.org/10.1136/ bmjopen-2014-006350).

Received 13 August 2014 Revised 25 October 2014 Accepted 18 November 2014

CrossMark

\footnotetext{
${ }^{1}$ Department of Epidemiology and Public Health, Swiss Tropical and Public Health Institute, Basel, Switzerland ${ }^{2}$ University of Basel, Basel, Switzerland

${ }^{3}$ Centre for Health Research and Development, The Maharashtra Association of Anthropological Sciences, Pune, Maharashtra, India
}

Correspondence to Neisha Sundaram; neisha. sundaram@unibas.ch

\section{ABSTRACT}

Objective: To identify and compare sociocultural features of pandemic influenza with reference to illness-related experience, meaning and behaviour in urban and rural areas of India.

Design: Cross-sectional, mixed-methods, cultural epidemiological survey with vignette-based interviews. Semistructured explanatory model interviews were used to study community ideas of the 2009 influenza pandemic. In-depth interviews elaborated respondents' experience during the pandemic.

Setting: Urban and rural communities, Pune district, western India.

Participants: Survey of urban $(n=215)$ and rural $(n=221)$ residents aged between 18 and 65 years. In-depth interviews of respondents with a history of 2009 pandemic influenza $(\mathrm{n}=6)$.

Results: More urban $(36.7 \%)$ than rural respondents $(16.3 \%, p<0.001)$ identified the illness in the vignette as 'swine flu'. Over half $(56.7 \%)$ believed the illness would be fatal without treatment, but with treatment $96 \%$ predicted full recovery. Worry ('tension') about the illness was reported as more troubling than somatic symptoms. The most common perceived causes - 'exposure to a dirty environment' and 'cough or sneeze of an infected person'-were more prominent in the urban group. Among rural respondents, climatic conditions, drinking contaminated water, tension and cultural ideas on humoral imbalance from heatproducing or cold-producing foods were more prominent. The most widely reported home treatment was herbal remedies; more rural respondents suggested reliance on prayer, and symptom relief was more of a priority for urban respondents. Government health services were preferred in the urban communities, and rural residents relied more than urban residents on private facilities. The important preventive measures emphasised were cleanliness, wholesome lifestyle and vaccines, and more urban respondents reported the use of masks. In-depth interviews indicated treatment delays during the 2009 pandemic, especially among rural patients.

Conclusions: Although the term was well known, better recognition of pandemic influenza cases is needed, especially in rural areas. Improved awareness,

\author{
Strengths and limitations of this study
}

- Consideration of community experience, meaning and behaviour to inform effective preparedness and control of pandemic influenza.

- Cultural epidemiological methods identify patterns of relevant social and cultural features of pandemic influenza.

- Urban and rural perceptions, priorities and illness behaviour have similar and distinctive features that are clarified locally.

- Integrated quantitative survey and qualitative ethnographic methods and triangulation effectively clarify relevant community experience for pandemic preparedness.

- Findings may change over time and in response to social changes or epidemics; relatively high non-participation rate.

access to treatment and timely referrals by private practitioners are also required to reduce treatment delays.

\section{INTRODUCTION}

Influenza is responsible for substantial mortality and morbidity in all age groups, across the globe. ${ }^{1}$ Three pandemics occurred in the previous century in 1918 ('Spanish flu'), 1957 ('Asian flu') and 1968 ('Hong Kong flu'). The 'Spanish flu' is believed to be the single most devastating disease outbreak in human history, resulting in approximately 50 million deaths worldwide. ${ }^{2}$ Influenza outbreaks caused by the novel influenza A virus H1N1 strain reached pandemic proportions in 2009 and the first influenza pandemic of the 21st century was declared. ${ }^{3} 4$ Although the 2009-2010 (H1N1) influenza pandemic was milder than expected, it is estimated to have been responsible for over 280000 deaths. ${ }^{5}$ 
Between May 2009 and August 2010, India had recorded 39977 laboratory confirmed cases and 2113 deaths from H1N1 influenza from 25 states and 6 union territories. ${ }^{6}$ The state of Maharashtra bore the highest mortality burden with 767 deaths $(36.3 \%$ of all H1N1-related deaths). Pune, Maharashtra's second largest city, recorded the first death in the country ${ }^{7}$ and was considered a hotspot of the 2009 influenza pandemic in India. 89

Pandemics can occur unpredictably and cause widespread disease. ${ }^{10}$ Containment of pandemic influenza depends extensively on the effectiveness of control measures, which in turn relies fundamentally on the public's willingness to collaborate. In order to foster this support, identifying community priorities and views on illness causation and prevention is critical. The study of cultural concepts of illness which are known to influence community expectations, behaviour and outcomes is necessary for locally relevant and effective pandemic policy planning. ${ }^{11}{ }^{12}$ Examination of community views on the 2009 influenza pandemic is relevant for pandemic preparedness and influenza control.

Although evidence of epidemiological differences in disease burden between urban and rural areas exist in Pune, ${ }^{9}$ little is known about differences between urban and rural concepts and priorities for influenza control among affected communities. Given the differences in urban-rural subcultures in terms of pandemic experiences, help-seeking, disease transmission, ${ }^{9}$ access to health facilities and living conditions, ${ }^{13}$ consideration of their commonalities and distinctiveness should benefit planning for pandemic preparedness. The aim of this study is to examine and compare sociocultural features of pandemic influenza with reference to the distribution of illness-related experience, meaning and behaviour across urban and rural communities in Pune district, India.

\section{METHODS}

Setting and study sites

The study was conducted in Pune district, western Maharashtra, India. The district has a population of 9.43 million, of which 5.75 million live in urban areas and 3.68 million in rural areas. ${ }^{14}$ The district headquarters is Pune city, which has recently experienced rapid growth. One of two major laboratories in India where virological testing was carried out during the pandemic, the National Institute of Virology, ${ }^{15}$ and a large manufacturer of influenza vaccines, the Serum Institute of India, are located in Pune.

Two urban study sites were densely-populated informal settlements in an area known as Sangamwadi and the middle-income neighbourhoods in an area called Erandawane in Pune city. ${ }^{16}$ The rural sites were in two subdistricts, Velhe and Mawal. Selection was based on their relative accessibility to Pune city. Of 17 villages in Velhe that were designated as relatively inaccessible, 10 were randomly selected for our study. Of 24 villages that were identified as accessible due to the presence of a road adjacent to the village, 10 were randomly selected. The number of persons selected from each village was proportionate to the village population.

\section{Instruments}

This study used semistructured interviews based on the framework of the explanatory model interview catalogue $\left(\right.$ EMIC) ${ }^{17}$ for cultural epidemiology ${ }^{18}$ and in-depth interviews. Both interviews were developed in workshops in Pune with anthropologists and public health experts. Instruments were translated into Marathi and refined based on the experience and analysis of pilot interview data and ethnographic focus group discussion data.

EMIC interviews were used to examine the distribution of community ideas of illness-related experience, meaning and behaviour. After questions about respondent characteristics, a vignette described in simple terms a person with characteristic clinical symptoms of influenza, set in the time period of January 2010. The sex, age group and residence of the character in the vignette and respondent were matched. This vignette-based approach elicited respondents' views on priority symptoms, perceived causes, help-seeking and prevention of the illness, based on a presentation of the condition, rather than recognition of its name. Respondents were also asked about their personal and household experience in the 2009 influenza pandemic. Complementary components of the data set included categorical and numeric data for quantitative comparative analysis and narrative data for qualitative thematic analysis and elaboration.

The agenda of in-depth interviews focused on actual experience and behaviour during the 2009 pandemic.

\section{Study design and sampling}

The cross-sectional study required a minimum sample of 328. The sample size calculation is based on the ability to detect a difference of 0.5 in prominence means (calculated for cultural epidemiological variables described in the 'data management and analysis' section) with $95 \%$ significance and $80 \%$ power for urban-rural comparisons. An additional $20 \%$ of interviews were planned to compensate for a possible shortfall in completed interviews.

Approximately 100 EMIC interviews were planned at each of the two urban and two rural sites. ${ }^{16}$ Households were randomly selected from the local registry of voters. Of the available records, voters' lists were the most comprehensive. However, they do not include persons or households not registered as voters. Thus, to avoid selection bias, the household of the person identified on the voters' list was located (but not interviewed) and the adjacent household to the right was approached for interview. Inclusion criteria were ages between 18 and 65 years, residency in Pune, conversational fluency in Marathi and ability to physically and mentally withstand an interview. If no member in the household satisfied 
the inclusion criteria or if there were no willing respondents, the neighbouring household to the right was approached, until a suitable respondent was found. An equal balance of men and women, and younger and older adults was maintained.

EMIC interview respondents who indicated having personal or household experience with influenza during the 2009 pandemic were approached for in-depth interviews. These in-depth interviews with directly affected persons supplemented the EMIC interview survey to elaborate findings with narrative accounts of the subgroup of respondents with personal pandemic illness experience.

Research assistants received extensive training in sampling procedures, obtaining informed consent, interviewing and data management during a 2-week workshop. They worked in teams of two, one conducting the interview and the other maintaining data records. Two supervisors reviewed data for accuracy and quality. Interviews were voice recorded with permission.

\section{Data management and analysis}

Quantitative data were double-entered into an electronic database using Epi Info V.3.5.3 (Centers for Disease Control and Prevention, USA), programmed with logic and range checks. For analysis of sociocultural features of illness, prominence of categories was calculated based on whether a response was spontaneous to an open question (assigned a value of 2) or in response to probing for that category (assigned a value of 1). When a category was identified as most important among all, it was assigned an additional value of 3. Mean prominences were calculated for each category, with a range of $0-5$. Through such consideration of prominence, categories were evaluated based on relative importance ascribed to them. Prominence means for categories were compared between urban and rural groups using the Wilcoxon rank-sum test, while proportions were compared using Fisher's exact test. Analysis of quantitative data was performed with SAS V.9.2 (SAS Institute, USA) and STATA V.12 (StataCorp LP, USA).

Narrative data for EMIC and in-depth interviews were entered in a word processor in Marathi using a unicode Devanagari font. After translation into English, data were imported into MAXQDA 11 (VERBI Software, Germany), using techniques for automatic first-level coding for narratives in response to specific questions. Deductive and inductive coding approaches were applied. Thematic similarities and differences between urban and rural narratives were systematically analysed. Variables from the quantitative data set were imported into MAXQDA to enable selection of narratives of interest, facilitating the integrated analysis of quantitative and qualitative data.

\section{RESULTS}

Sample characteristics

Field data were collected between July 2012 and February 2013. Among the community members approached for interview, 50 in urban areas and 10 in rural areas did not satisfy the inclusion criteria and were excluded. A total of 822 persons approached refused to participate, and the refusal rate was higher in urban $(76 \%, \mathrm{n}=681)$ compared to rural areas $(36 \%, n=141)$. The reason for refusal indicated by the majority was that they were too busy to participate in the interview. Incomplete interviews $(n=35)$ were excluded from the analysis.

Of the 436 completed interviews, approximately half were with women and half were from urban and rural sites (table 1). More urban residents were postgraduates, graduates or had higher secondary school education, and more rural respondents had no education. Urban household incomes were higher than rural household incomes and more were reported as reliable and dependable. The most commonly reported occupation was agriculture among rural respondents. Self-employment or employment with a private organisation was most frequently reported by urban respondents.

\section{Awareness of pandemic influenza}

A third of respondents identified the condition as a respiratory illness (table 2) and more urban respondents ( $36.7 \%$ vs. $16.3 \%$ rural) identified it as 'swine flu'. Alternative names for the illness condition such as H1N1 influenza or pandemic flu were seldom used. Towards the end of the interview, those who had not mentioned swine flu were specifically asked if they had heard of it-a majority said they had and only $10.3 \%$ of the entire sample $(3.3 \%$ urban, $17.2 \%$ rural) had not.

Illness identification was based on the following themes: physical symptoms, time period indicated in the vignette, and information available on contemporary diseases or ongoing outbreaks. A 45-year-old urban woman who identified the illness through symptoms indicated the logic used in identification by stating:

\footnotetext{
"It must be either dengue or swine flu. It could be chikungunya, if she has joint pain. If there is no joint pain but she is suffering from body ache, then she may have swine flu or dengue. Swine flu is more probable because dengue is characterized by a facial rash while sore throat and cold are the symptoms of swine flu."
}

For others, the time period of occurrence defined the condition:

\footnotetext{
"Since it dates back to two years ago, it must be swine flu because it was on a high two years ago... swine flu is characterised by high fever." (28 years, rural woman).
}

The notion of swine flu as a new disease was common and contributed to illness identification. Information provided in the vignette associating the illness with an outbreak (multiple cases in the community) was also noted. The condition was sometimes conflated with dengue fever, inasmuch as a dengue outbreak was ongoing during the period of study interviews. A 65-year-old woman stated: 
Table 1 Sample characteristics of study respondents

\begin{tabular}{|c|c|c|c|c|}
\hline Sociodemographic features & Overall sample, $n=436$ & Urban sites, $\mathrm{n}=\mathbf{2 1 5}$ & Rural sites, $\mathrm{n}=\mathbf{2 2 1}$ & p Values \\
\hline \multicolumn{5}{|l|}{ Gender (\%) } \\
\hline Women & 50.7 & 50.2 & 51.1 & \\
\hline \multicolumn{5}{|l|}{ Age (years) } \\
\hline Median (IQR) $\dagger$ & $45(29-55)$ & $45(28-57)$ & $45(29-52)$ & \\
\hline \multicolumn{5}{|l|}{ Household size (number of persons) } \\
\hline Median (IQR)† & $5(4-7)$ & $5(3-6)$ & $5(4-7)$ & ** \\
\hline \multicolumn{5}{|l|}{ Occupation $(\%)^{\star \star \star} \ddagger$} \\
\hline Agriculture & 22.5 & 0.0 & 44.3 & *** \\
\hline Unskilled labour & 7.3 & 8.4 & 6.3 & \\
\hline Skilled labour & 4.6 & 6.5 & 2.7 & \\
\hline Self-employment & 9.9 & 11.6 & 8.1 & \\
\hline Business & 2.1 & 2.8 & 1.4 & \\
\hline Service (public) & 2.8 & 2.8 & 2.7 & \\
\hline Service (private) & 9.6 & 12.1 & 7.2 & \\
\hline Student & 5.0 & 6.0 & 4.1 & \\
\hline Housewife & 24.1 & 30.2 & 18.1 & ** \\
\hline Retired & 8.7 & 14.4 & 3.2 & 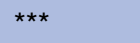 \\
\hline Unemployed & 3.4 & 5.1 & 1.8 & \\
\hline \multicolumn{5}{|l|}{ Highest education level attained $(\%)^{\star \star \star} \ddagger$} \\
\hline No education & 21.6 & 11.6 & 31.2 & 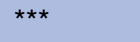 \\
\hline Less than primary & 7.3 & 7.9 & 6.8 & \\
\hline Primary school & 38.3 & 33.5 & 43.0 & * \\
\hline Secondary school & 12.8 & 14.9 & 10.9 & \\
\hline Higher secondary school & 10.3 & 14.0 & 6.8 & * \\
\hline Diploma/professional course & 1.6 & 2.3 & 0.9 & \\
\hline Graduation & 4.8 & 9.8 & 0.0 & 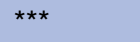 \\
\hline Postgraduation & 3.2 & 6.0 & 0.5 & 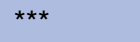 \\
\hline \multicolumn{5}{|l|}{ Years of school attended (years) } \\
\hline Median (IQR)† & $7(2-11)$ & $10(5-13)$ & $5(0-10)$ & $\star \star * *$ \\
\hline \multicolumn{5}{|l|}{ Marital status $s^{\star \star \star} \ddagger$} \\
\hline Single & 15.1 & 18.6 & 11.8 & \\
\hline Married & 77.3 & 73.0 & 81.4 & * \\
\hline Widowed & 7.6 & 8.4 & 6.8 & \\
\hline \multicolumn{5}{|l|}{ Religion ${ }^{\star \star \star} \ddagger$} \\
\hline Hindu & 84.4 & 74.9 & 93.7 & 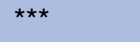 \\
\hline Muslim & 3.4 & 6.5 & 0.5 & $* \star \star$ \\
\hline Christian & 1.1 & 2.3 & 0.0 & * \\
\hline Neobuddhist & 10.8 & 15.8 & 5.9 & $* \star \star$ \\
\hline \multicolumn{5}{|l|}{ Social category ${ }^{* *} \ddagger$} \\
\hline Scheduled caste or tribe & 25.0 & 38.1 & 12.2 & $\star \star \star *$ \\
\hline Other backward class & 8.3 & 10.2 & 6.3 & \\
\hline Open/general category & 59.6 & 41.4 & 77.4 & $* \star *$ \\
\hline Vimukta jati nomadic tribes & 3.4 & 2.8 & 4.1 & \\
\hline Undisclosed & 3.4 & 7.0 & 0.0 & 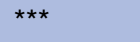 \\
\hline \multicolumn{5}{|c|}{ Monthly household income (Indian Rupees) } \\
\hline Median (IQR)† & $10000(5000-17500)$ & $11000(6000-22500)$ & $7250(3375-13250)$ & 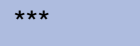 \\
\hline Unable to provide a response $(\%) \ddagger$ & 21.6 & 13.5 & 29.4 & 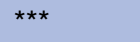 \\
\hline \multicolumn{5}{|l|}{ Household income reliability (\%)‡ } \\
\hline Reliable and dependable & 49.1 & 60.9 & 37.6 & 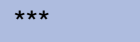 \\
\hline Not reliable and dependable & 44.5 & 35.3 & 53.4 & *** \\
\hline No response & 6.4 & 3.7 & 9.0 & * \\
\hline
\end{tabular}

${ }^{*} \mathrm{p} \leq 0.05,{ }^{* *} \mathrm{p} \leq 0.01,{ }^{* * *} \mathrm{p} \leq 0.001$.

tWilcoxon test.

†Pearson $\chi^{2}$ or Fisher's exact test. 
Table 2 Identification of illness presented in the vignette

\begin{tabular}{|c|c|c|c|c|}
\hline IIIness identified as* & $\begin{array}{l}\text { Overall sample, } \\
n=436\end{array}$ & $\begin{array}{l}\text { Urban sites, } \\
n=215\end{array}$ & $\begin{array}{l}\text { Rural sites, } \\
n=221\end{array}$ & p Values† \\
\hline Group 1: Respiratory illness & 30.7 & 40.9 & 20.8 & $<0.001$ \\
\hline Swine flu, H1N1 influenza or Pandemic flu & 26.4 & 36.7 & 16.3 & $<0.001$ \\
\hline Seasonal or common flu & 1.6 & 1.9 & 1.4 & 0.721 \\
\hline Viral (fever/infection) & 0.5 & 0.9 & 0.0 & 0.243 \\
\hline Common cold & 0.9 & 0.9 & 0.9 & 1.000 \\
\hline Combinations of fever, chills, cough & 1.4 & 0.5 & 2.3 & 0.216 \\
\hline Group 2: Other specified conditions & 38.8 & 38.1 & 39.4 & 0.844 \\
\hline HIVIAIDS & 3.2 & 2.8 & 3.6 & 0.787 \\
\hline Tuberculosis (TB) & 9.6 & 10.2 & 9.0 & 0.746 \\
\hline Typhoid & 3.4 & 1.9 & 5.0 & 0.113 \\
\hline Dengue & 8.3 & 11.2 & 5.4 & 0.036 \\
\hline Malaria & 5.3 & 4.7 & 5.9 & 0.670 \\
\hline Other & 8.9 & 7.4 & 10.4 & 0.316 \\
\hline Group 3: Unable to specify & 30.5 & 20.9 & 39.8 & $<0.001$ \\
\hline Cannot say or undecided & 30.5 & 20.9 & 39.8 & $<0.001$ \\
\hline
\end{tabular}

"If the disease was spreading in the neighbourhood then the name would have been mentioned on TV... swine $\mathrm{flu}$, it is also called dengue. It was widespread in Punedengue and swine flu-both are the same disease. That one disease has two names."

More rural respondents were unable to identify the illness by a name (39.8\% vs $20.9 \%$ urban). Explanations were similar in both areas: (1) simply not knowing or being uneducated was commonly cited, (2) some indicated that only a doctor can name the illness, not a layman, (3) others displayed confusion between many well-known diseases. For example, a 46-year-old rural woman stated:

"Cough leads to TB. There are many different illnesses, isn't it? There are different kinds of fever. Some contract Malaria, while others could suffer from typhoid or dengue. Some people take time to recover. I won't be able to name the illness."

\section{Perceived seriousness of illness}

No urban-rural differences were apparent for severity of the illness: $46.6 \%$ of the whole sample said it was very serious and $31.2 \%$ said it was serious, but $8.7 \%$ thought it was not a serious illness. The remaining respondents were unable to provide a reply. Without treatment, $56.7 \%$ believed the illness would be fatal, $38.5 \%$ believed the condition would worsen but not necessarily lead to death and less than $1 \%$ anticipated a full recovery. With treatment, however, $96.1 \%$ predicted a complete recovery, and less than $2 \%$ anticipated fatality or worsening symptoms.

\section{Categories of distress}

Social or emotional categories of distress had greater prominence in the urban than in the rural group: distress caused by isolation from others (prominence: urban=1.047, rural=0.742, $\mathrm{p}<0.001$ ) and sadness or anxiety resulting from the illness (prominence: urban=1.363, rural=1.136, $\mathrm{p}=0.004)$. More rural respondents emphasised physical symptoms such as chills $(p=0.001)$, nasal congestion $(p<0.001)$ and breathlessness $(\mathrm{p}=0.024)$.

In the overall sample, worry ('tension') was most frequently reported $(11.7 \%$ of sample) as most troubling among all physical symptoms and social or financial problems from the illness. This was followed by concern about the course of illness $(8.5 \%)$, loss of income $(6.7 \%)$, costs from transport, food and drugs $(6.2 \%)$ and interference with social relations $(5.7 \%)$. The most troubling physical symptoms were identified as cough $(5.7 \%)$ and fever $(5.5 \%)$. No urban-rural differences were present in these findings.

\section{Perceived causes}

The two most prominent perceived causes, improper sanitation, dirty environment and cough or sneeze of an infected person (airborne transmission), were reported with greater prominence among urban respondents (figure 1). Explanations for a dirty environment were similar among all respondents and included references to accumulated filth, poor drainage, open gutters and sewage, open defecation and a general lack of cleanliness in the surroundings. Narratives regarding airborne transmission largely referred to breathing in germs or droplets from another person's cough or sputum. However, details were elaborated with reference to other categories by some. For example:

"The germs could enter your body through inhalation while interacting with an infected person. The germs may spread through the air due to sneeze or cough. It 
Causes: Ingestion, Environmental or Social

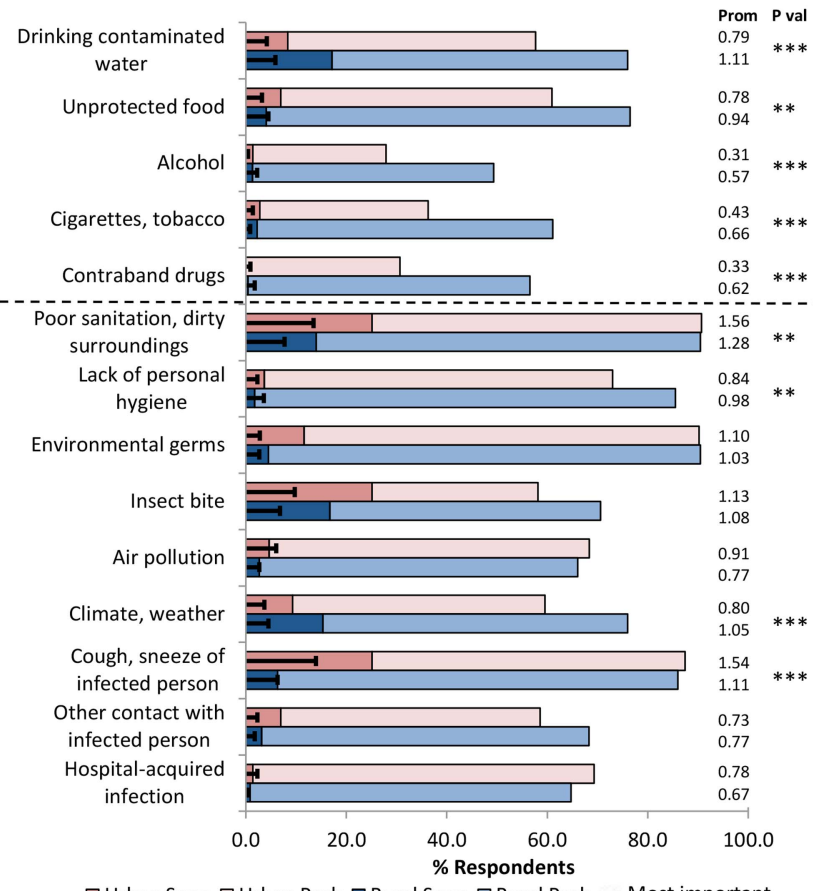

$\square$ Urban Spon $\square$ Urban Prob $\square$ Rural Spon $\square$ Rural Prob $\rightarrow$ Most important $* * *$ **
Causes : Health, Psychological, Cultural

val $* *$ $* * *$ $* * *$

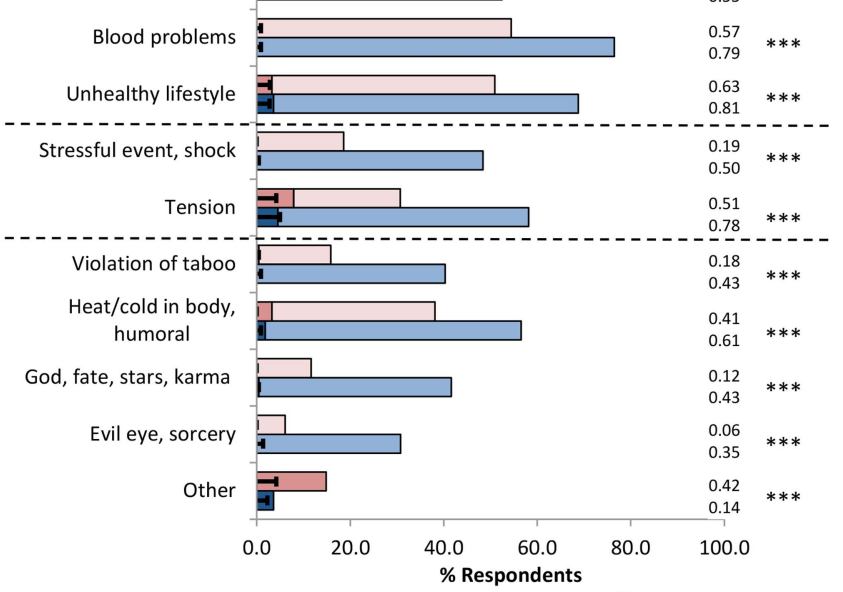

口Urban Spon $\square$ Urban Prob $\square$ Rural Spon $\square$ Rural Prob $\rightarrow$ Most important

Figure 1 Spon: percentage of respondents who identified the category spontaneously (value=2). Prob: percentage of respondents who identified the category on probing (value $=1$ ). Most important: percentage of respondents who identified the category as most important among all others (value $=3$ ). Prom: mean prominence scores calculated for each site. Wilcoxon test used to compare prominence scores between sites. ${ }^{*} p \leq 0.05,{ }^{* \star} p \leq 0.01,{ }^{\star * \star} p \leq 0.001$.

also may have been caused due to mosquito bite, exposure to mosquitoes or infected tissue paper present on garbage containers." (Man, 48 years, urban).

No urban-rural differences were present for insect bite, the third most prominently reported cause. Mosquitoes were the most commonly mentioned insect vector.

Drinking contaminated water ranked third in prominence in the rural group and ninth in the urban group. Most urban respondents attributed this cause to germs or dirt in the water. In the rural sites, however, in addition to this explanation, another theme emerged referring to a change in drinking water. This did not refer to contaminants in the water; it had to do with merely drinking water in different places. The narrative of a 35-year-old rural woman illustrates this theme:

\footnotetext{
"This illness is also caused due to the water, the drinking water... Say we go to a particular village, and drink the water there, and then we go to another village and drink the water over there, some people cannot tolerate the change. Then we catch a cold because of drinking water of different villages."
}

The perception of a change in water as a cause was reported by approximately $35 \%$ of rural, but less than $1 \%$ of urban respondents who identified drinking water as a perceived cause.
More rural than urban respondents reported climate or weather as a perceived cause and a few themes underlay its meaning. A majority referred to a change in weather or fluctuations in temperature, as in the following narrative:

"Look at this climate. It happens due to such air, such climate. The climate varies between cold and hot. Sometimes it is hot while sometimes it is cold. This illness is related to the climate hence occurs due to it" (65-year-old rural man).

Others attributed the illness to getting wet in the rain or being exposed to cold weather. Exposure to sunny weather was also reported as a cause, but mainly by rural respondents.

'Tension' was reported as a perceived cause by $44.6 \%$, with greater rural prominence. The term appeared selfexplanatory to most and it was often indicated as a cause without further elaboration. When explained, respondents referred to mental worries caused by household and economic pressures leading to illness. A 63-year-old woman elaborated:

"It happens because of worrying; worry could be due to household matters, tension or a difficult financial condition. If nobody is earning or family members are not getting along well with each other, then the person feels dejected and gets the illness." 
Heat or cold in the body was reported with higher prominence at the rural sites, but explained in similar ways in both urban and rural areas. This cause referred to cultural ideas about humoral imbalances leading to illness as a result of consuming foods that are sour, cold, cold-producing (eg, yoghurt, cucumber), heatproducing (eg, chicken, heavily spiced food), unsuitable (eg, guava) or oily. Other cultural or supernatural causes such as 'violation of taboo', 'god, fate, karma', 'evil eye, sorcery' and causes related to addiction (alcohol, tobacco, contraband drugs) were also emphasised by more rural than urban respondents.

\section{Help-seeking}

\section{Home-based treatment}

Rural respondents had a higher prominence than urban respondents for prayer among home-based treatments (figure 2). Drinking warm liquids and gargling, measures more directly related to alleviation of symptoms, however, had greater prominence among urban respondents. The value of prayer was seldom mentioned spontaneously at either site, but was reported by $61 \%$ on probing and highlighted as most important by $13.1 \%$ of all respondents.

Herbal remedies were the most prominent category in the overall sample. Accounts included frequent mention of kadha-an herbal concoction brewed at home. The second and third most prominently reported categories were doing nothing and feeding the patient with strength-providing food. Respondents who suggested no home treatment typically emphasised the priority of rushing the patient to hospital as quickly as possible.

\section{Help-seeking outside the home}

Government and private health facilities, and informal help were widely reported outside sources of help seeking (figure 2). More urban than rural respondents emphasised the value of government hospitals. Narrative accounts indicated that this preference among urban respondents tended to be specifically for treating swine flu. Rural respondents, however, emphasised the value of private facilities, even though they were acknowledged to be more expensive and hence not always feasible. Narrative data indicated a general preference in both groups for private over government health facilities, inasmuch as they were perceived to be more easily accessible, less crowded with shorter waiting times and to offer better treatment and quality of care.

Significantly more rural respondents reported relying on local health workers, informal help from friends, neighbours or relatives, traditional healers and faith healers. Although few spontaneously reported visiting a traditional healer (vaidu, jadibooti wala) or a faith healer, probing revealed that $37.8 \%$ and $30.7 \%$, respectively, of all respondents were likely to. This was usually after visiting an allopathic centre, and if the treatment was ineffective or services inadequate. The order of preference for outside treatment was explained succinctly by a 42-year-old rural man,
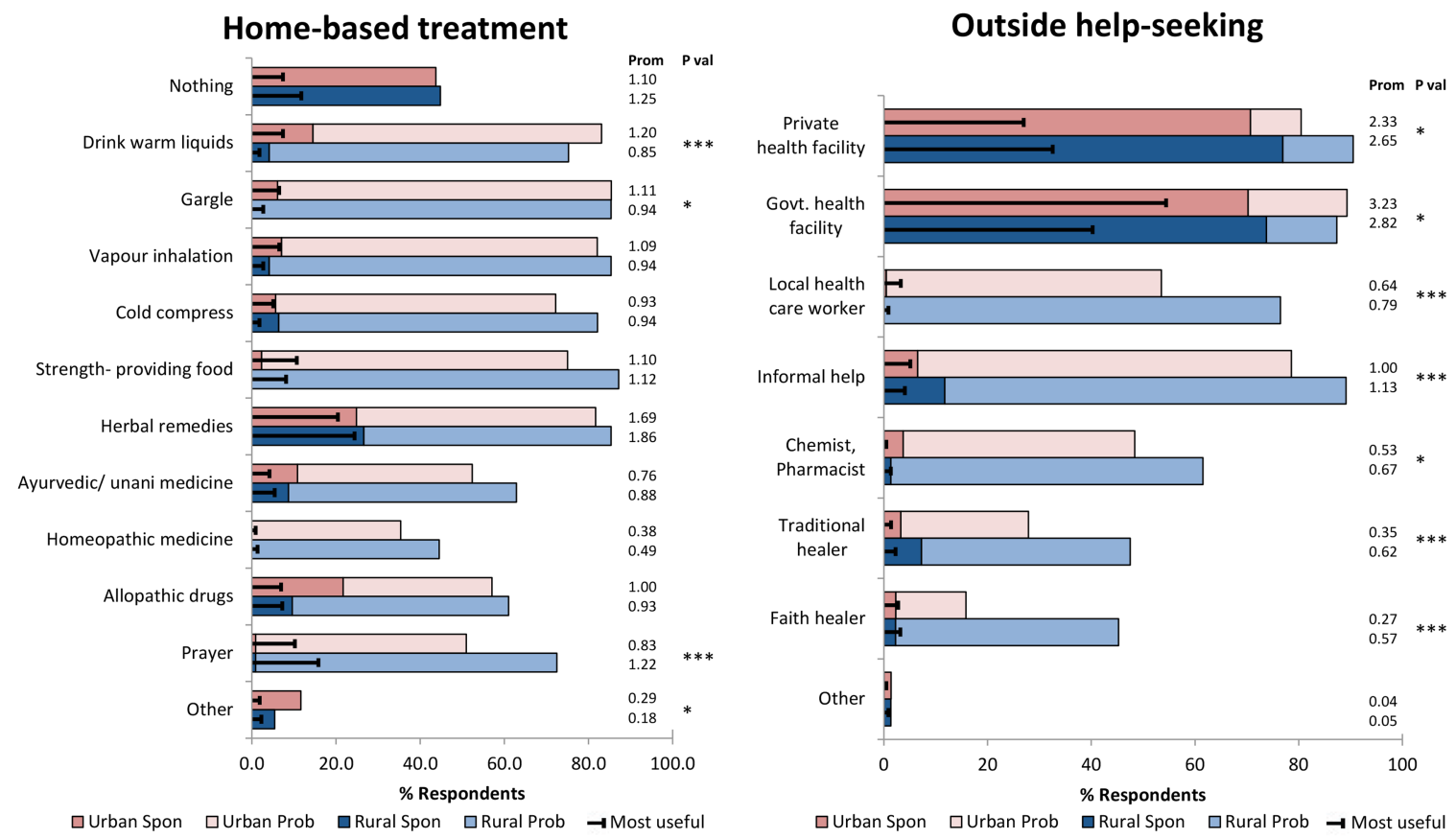

Figure 2 Spon: percentage of respondents who identified the category spontaneously (value=2). Prob: percentage of respondents who identified the category on probing (value $=1$ ). Most important: percentage of respondents who identified the category as most important among all others (value $=3$ ). Prom: mean prominence scores calculated for each site. Wilcoxon test used to compare prominence scores between sites. ${ }^{*} p \leq 0.05,{ }^{* *} p \leq 0.01,{ }^{* \star *} p \leq 0.001$. 
Figure 3 Spon: percentage of respondents who identified the category spontaneously (value=2). Prob: percentage of respondents who identified the category on probing (value $=1$ ). Most important: percentage of respondents who identified the category as most important among all others (value=3). Prom: mean prominence scores calculated for each site. Wilcoxon test used to compare prominence scores between sites. ${ }^{*} \mathrm{p} \leq 0.05$, ${ }^{* *} \mathrm{p} \leq 0.01,{ }^{* * *} \mathrm{p} \leq 0.001$.

\section{Prevention}

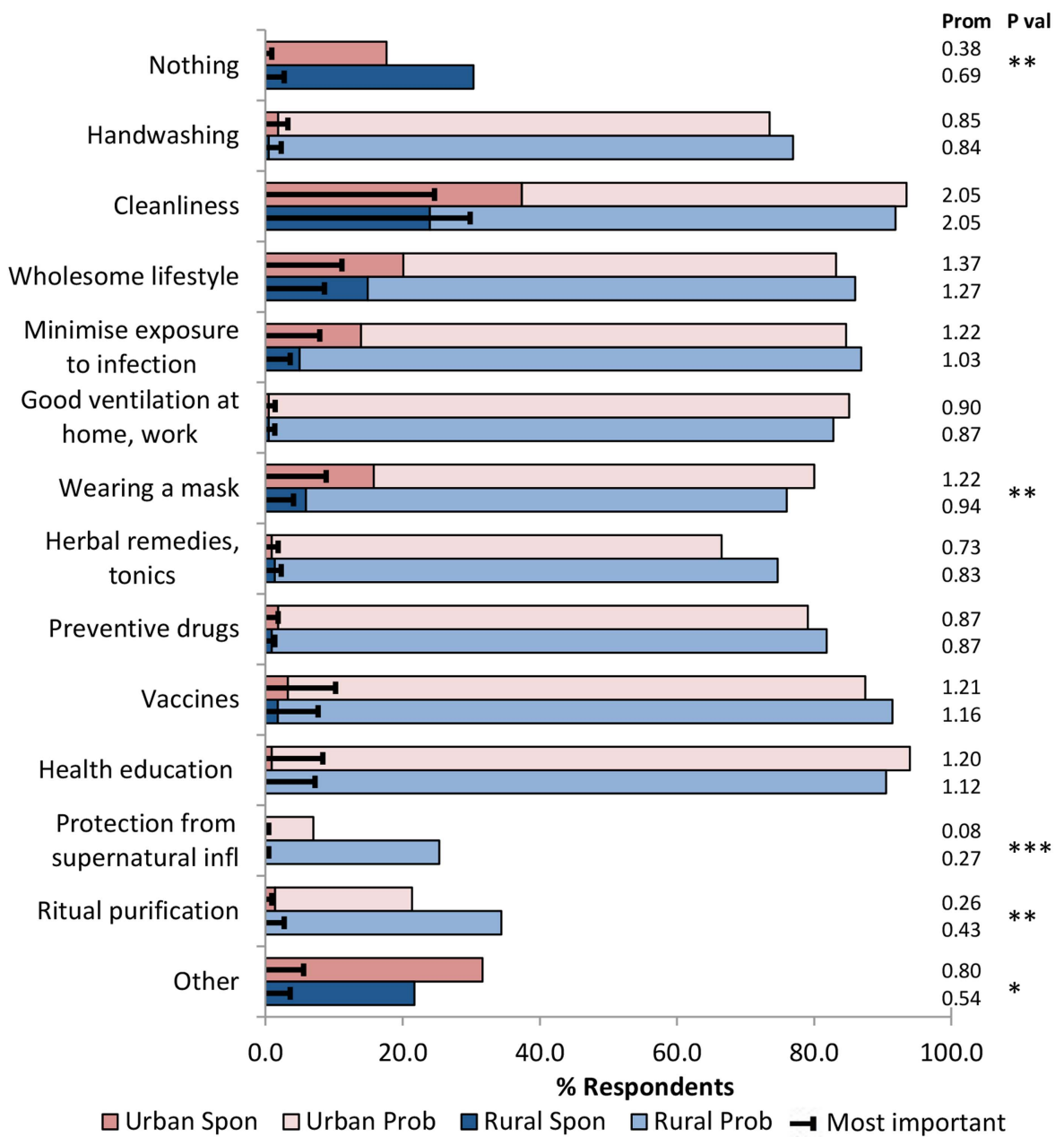

$\square$ Urban Spon
"If there is no other option [owing to financial constraints] then he would go to a doctor in the government hospital. If nothing happens there he would go to a private doctor. If there again he feels that nothing is happening, he would then go to the religious leader, bhagat (faith healer) and so on."

\section{Methods of prevention}

For prevention, more urban respondents emphasised the value of wearing masks, and more rural respondents suggested doing nothing, because the future was unpredictable. More rural respondents emphasised the value of ritual purification (agnihotra or dhoop-a Hindu religious process of purifying the atmosphere with smoke from a specially prepared fire) or protection from supernatural influence, although both were among categories with the lowest prominence.

Among overall community ideas about preventing the illness, cleanliness had the highest prominence, followed by a wholesome lifestyle-which referred to a proper diet and exercise-and then vaccines (figure 3). Cleanliness referred to both personal hygiene as well as cleanliness of the home and surroundings. Contradictory explanations were provided in the urban and rural areas for physical exercise in illness prevention. Rural respondents emphasised a need to avoid overexertion from excessive work and exposure to the sun, but urban respondents highlighted the value of regular exercise. Vaccines were mentioned spontaneously by only $2.5 \%$ of respondents, but $89.4 \%$ acknowledged its value when probed. Hand washing was seldom mentioned spontaneously or identified as most important and ranked 10th in prominence among all prevention categories. Minimising exposure to infection and using masks ranked fifth and sixth in prominence, respectively.

\section{Experience with swine flu}

Of the 436 persons interviewed, three reported a personal history of swine flu during the 2009 pandemic, and four a family history in the household. Three in-depth interviews each at the urban and rural sites were conducted among these persons.

In-depth interviews elaborated a typical course of first help seeking at private clinics and a period without adequate treatment before referral to a larger hospital, if they were referred at all. After 4 days of medication had failed to alleviate symptoms for two of the urban 
patients, the private-clinic doctor recommended the government-run Naidu hospital; the third urban respondent visited that hospital of her own accord, and all three acknowledged receiving free treatment at the Naidu hospital. Only one rural respondent was referred to a government-run hospital, and that referral came only after 8 days of injections and medication at the private facility. This respondent reported spending INR 25 000-30000(approximately US\$600) at the private hospital, compared with free treatment at the government hospital. The other two rural respondents were referred to private hospitals. One of them was transferred to three different private health facilities before receiving antiviral treatment and reported spending INR 500000 (US\$10 000) on hospital bills, and the other spent 12 days in an intensive care unit, which cost her INR 90000 (US\$1900).

Only two of the six respondents provided a valid biomedical explanation for the cause of their swine flu, saying they caught it from other infected persons. Perceived causes reported by the others were getting wet in the rain, addiction to smokeless tobacco, air pollution, eating cold foods and mosquito bite.

\section{DISCUSSION}

This is the first study to examine community-reported experience, meaning and behaviour of pandemic influenza in India using a cultural epidemiological approach. Taking community perceptions into account enables planning that is more responsive to local needs and thereby strengthens trust, authority and effectiveness of public health action. ${ }^{19}$ Most studies evaluating pandemic influenza in India have focused on the burden and clinical response. ${ }^{8}$ 20-24 A few have considered knowledge, attitudes and practices. ${ }^{25} 26$ The scope of interest and methods have been limited in their ability to consider and compare the priority of community ideas based on how they are reported and what they mean to respondents. Our approach benefits from a design integrating quantitative and qualitative methods for community study.

\section{Improving awareness in general and influenza recognition}

The vast majority of respondents were aware of pandemic influenza and considered it a serious illness that required treatment. Although 90\% knew about the illness called swine flu, only $26 \%$ identified it from the characteristic symptoms (sore throat, cough, runny nose, body ache, fatigue and constant high fever) and setting described in the vignette. Confusion and conflation with other diseases were notable. Despite the priority of treatment during the pandemic outbreak, problems in community identification of risk associated with non-specific symptoms and poor awareness may have compromised timely, appropriate help seeking, diagnosis and treatment. In addition to general awareness, more attention to characteristic presentations, rather than just the name of the pandemic disease, appears warranted. Although common symptoms associated with laboratory-confirmed 2009 H1N1 influenza among patients diagnosed at hospitals in India-fever ${ }^{20} 27$ and $\operatorname{cough}^{27}$ were the most troubling physical symptoms identified by our study respondents, they did not necessarily relate these symptoms to pandemic influenza in a characteristic case presentation.

Although awareness of biomedically relevant airborne transmission of the illness was widely recognised, other causes were also identified, even by respondents with a history of pandemic influenza. This finding is consistent with another study in India that found high-school students referred to transmission of swine flu through food, water and mosquito bite. ${ }^{26}$ Pluralism in the attribution of causes was notable in our study, including psychosomatic ideas about the role of tension and cultural ideas about the impact of humoral imbalances in the body resulting from effects of certain foods (referring to the cultural physiology rooted in concepts of Ayurveda ${ }^{28}$ ) that coexist among various environmental, social and ingestion-related ones.

\section{Interventions for control}

Pandemic influenza control relies on prevention through vaccination, limiting exposure by promoting hand washing and minimising social contact. Timely treatment with supportive care and antivirals are also important response measures. ${ }^{29-31}$

\section{Priority for vaccination and promoting awareness of non-pharmaceutical interventions}

Vaccination is a critical measure for influenza control to prevent the spread of the virus and mitigate the impact of the disease. ${ }^{10}{ }^{30}$ Community recognition of vaccination, which was seldom reported spontaneously, was acknowledged by most respondents, but with relatively lower priority than cleanliness and lifestyle. A community-based study in Rajasthan, using selfadministered questionnaires, found that herbal treatment had been reported as least effective and vaccines as most effective for prevention of swine flu. ${ }^{25}$ Inasmuch as our study asked about an illness described in a vignette, rather than a named disease, it was a different approach. While our findings suggest a priority for vaccination based on the influence of ideas about perceived risk, ${ }^{32}$ a further study of anticipated acceptance and actual uptake of vaccines for pandemic influenza in Pune is needed.

Hand washing is an important component of the public health response to influenza, although compliance may be difficult to motivate; effects are modest but enhanced in combination with face masks. ${ }^{33}$ These measures are especially important before a vaccine is developed for a specific strain of pandemic influenza. India's pandemic preparedness and response plan for influenza control acknowledges the role of hand washing, social distancing and using masks as recommended nonpharmaceutical interventions. ${ }^{34}$ Our study respondents prioritised other non-pharmaceutical forms of 
prevention (eg, wholesome lifestyle and health education) for the illness described in the vignette. Respondents' emphasis on a wholesome lifestyle may stem from messages disseminated to communities during the pandemic, ${ }^{35}$ and additional efforts may be needed to promote community awareness and hand hygiene behaviour. Although they were acknowledged in rural areas, face masks were less of a priority and hence less likely to be used than in urban areas. In any case, promoting nonpharmaceutical interventions appears to be complementary and may enhance vaccination uptake. ${ }^{36}$

\section{Medical care and treatment delay}

Timely help seeking, supportive care and admission in intensive care units when indicated are critical determinants of survival for patients with serious disease at risk of respiratory failure. ${ }^{37}$ Treatment delay of more than 2 days with antivirals after onset of symptoms has been associated with increased risk of death, ${ }^{38}$ although recent reviews question the role of antivirals for pandemic influenza control. ${ }^{4041}$ During the 2009 pandemic in India, intensive care units or ventilators were not available at all hospitals ${ }^{42}$ and antivirals were made available mainly through the public health system. ${ }^{34}$ Treatment at government hospitals or private hospitals with adequate facilities enables quicker access to critical care. In our study, in-depth interview elaboration of illness experience for both urban and rural respondents with a history of pandemic influenza was consistent. They had all first consulted a private general practitioner (GP) without improvement in their condition. For these patients, the minimum time lag between first help-seeking at a private facility and referral to a larger hospital was 4 days. Problematic delay in hospital admission has also been noted in other studies. ${ }^{27}$ Our data suggest that lack of awareness on the importance of adequate facilities for treating pandemic influenza, lack of access to such larger hospitals, poor perception of government health facilities, compared with private (reported in other studies too ${ }^{43-45}$ ), and delayed referrals by private GPs may all lead to delayed treatment, especially for rural respondents.

As a component of the strategy for pandemic disease control, treatment delays may be avoided by (1) sensitising the public to the capacity of government facilities for treating pandemic influenza, (2) improving access to healthcare in rural areas (3) reshaping public perception of the quality of government health facilities and (4) training private GPs to identify and quickly refer potential influenza cases to hospitals with required treatment facilities.

\section{Urban-rural differences}

Analysis of illness experience showed that urban respondents were relatively more attentive to psychosocial symptoms, and rural respondents were more likely to emphasise somatic symptoms of illness. Reliance on the labour-intensive basis of their agricultural livelihood may explain that. Rural respondents were also more likely to prioritise environmental causes (climate), limited resources (contaminated food and drinking water) and addictive behaviours. Rural respondents placed relatively more value in traditional cultural responses, both prayer as a home-based response and magicoreligious protective measures for prevention. They were also more likely to acknowledge the futility of attempting to prevent the illness. Urban respondents focused relatively more on measures to alleviate symptoms. The value of a face mask also had higher prominence in the urban areas.

Less overall awareness at rural sites may be explained in part by the lower disease burden ${ }^{9}$ and reduced exposure to the media in rural areas of Pune during the 2009 pandemic. Rural areas, however, were also affected by the rapid spread and mortality as the pandemic progressed. ${ }^{46}$ The challenge is especially clear in rural areas to improve the awareness of pandemic influenza, including its causation, transmission, prevention and timely appropriate help-seeking. At the urban sites, where pandemic influenza-specific knowledge was more apparent, the need to improve awareness and recognition of cases nevertheless also remains challenging.

\section{Limitations}

Data collection started 2 years after the officially declared end of the pandemic in $2010^{47}$ and recall bias among respondents is a potential limitation of this study. However, extensive media coverage of 'swine flu' in Pune during that period and persisting subsequently ${ }^{48} 49$ is likely to have maintained public memory of the illness. We also recognise the high refusal rate, particularly in the urban community, as a limitation. Refusals were carefully noted, enabling us to document this problem. Although non-participation is increasingly problematic for community epidemiological responses, non-participation is not necessarily equivalent to nonparticipation bias. ${ }^{50}$ Nevertheless, findings must be regarded as suggestive rather than conclusive. Meetings with local leaders in rural areas, prior to data collection, were intended to enlist cooperation. This was not possible at the urban site. Plans for community and professional dissemination of research findings aimed to highlight the value of the study for respondents and thereby motivate their participation.

Findings should be considered with reference to both the historical context-reflecting social changes and epidemics-and regional contexts across India and in other countries. Generalisation from the EMIC survey component of the study is therefore appropriate with reference to similar sociocultural settings, acknowledging differences elsewhere. Nevertheless, we expect the approach and methods for study of sociocultural features reported here to be generalisable and appropriate for consideration where cultural differences indicate the relevance of cross-site differences and the value of comparative study. Complementary qualitative elaboration, which may not be generalisable in other settings, provides locally relevant detail for health services. 


\section{CONCLUSION}

Comparison of sociocultural features of urban and rural communities has identified common needs to better distinguish recognition of the illness from names of the condition and particular challenges of access, especially in rural areas. Consideration of community ideas and experience should guide effective planning for pandemic preparedness. The integrated cultural epidemiological approach enhanced by complementary qualitative in-depth interviews indicates a way to proceed. The value of such findings should be enhanced by community dissemination and to health policymakers.

Acknowledgements The authors are grateful to all study participants for sharing their thoughts and experiences. They also thank the field supervisors and field interviewers for their efforts and dedication.

Contributors NS was involved in the design and coordination of the study, participated in data collection, analysed the data and wrote the manuscript. CS was involved in the design and coordination of the study and revised the manuscript. VP was involved in the design and coordination of the study, participated in data collection and revised the manuscript. AK was involved in the design and coordination of the study, oversaw data collection and revised the manuscript. MGW initiated the study, participated in the design and coordination of the study and critically revised and reviewed the manuscript. All authors have read and approved the final manuscript.

Funding This work was supported by the WHO, Switzerland.

Competing interests None.

Ethics approval The study protocol received ethical approval from the institutional ethics committee of the Maharashtra Association of Anthropological Sciences, Pune, the WHO Research Ethics Review Committee and the Ethics Commission of Basel. Interviews were conducted after obtaining written informed consent. No financial or other incentives were given to respondents for participation. Data collected in this study are maintained with utmost confidentiality and anonymised for reporting.

Provenance and peer review Not commissioned; externally peer reviewed.

Data sharing statement No additional data are available.

Open Access This is an Open Access article distributed in accordance with the Creative Commons Attribution Non Commercial (CC BY-NC 4.0) license, which permits others to distribute, remix, adapt, build upon this work noncommercially, and license their derivative works on different terms, provided the original work is properly cited and the use is non-commercial. See: http:// creativecommons.org/licenses/by-nc/4.0/

\section{REFERENCES}

1. World Health Organization. Vaccines against influenza WHO position paper-November 2012. Wkly Epidemiol Rec 2012;87:461-76.

2. Taubenberger JK, Morens DM. 1918 Influenza: the mother of all pandemics. Emerg Infect Dis 2006;12:15-22.

3. Scalera NM, Mossad SB. The first pandemic of the 21st century: a review of the 2009 pandemic variant influenza $A(\mathrm{H} 1 \mathrm{~N} 1)$ virus. Postgrad Med 2009;121:43-7.

4. World now at the start of 2009 influenza pandemic. Statement to the press by WHO Director-General Dr Margaret Chan (12 June 2009). World Health Organization. http://www.who.int/mediacentre/news/ statements/2009/h1n1_pandemic_phase6_20090611/en/index.html (accessed 20 Jan 2013).

5. Dawood FS, luliano AD, Reed C, et al. Estimated global mortality associated with the first 12 months of 2009 pandemic influenza $A$ H1N1 virus circulation: a modelling study. Lancet Infect Dis 2012;12:687-95.

6. Situational updates-Influenza A H1N1 (29 Aug 2010). Government of India: Directorate General of Health Services-Ministry of Health \& Family Welfare. http://mohfw-h1n1.nic.in/August2010.html (accessed 20 Feb 2014).
7. First India H1N1 death is girl in Pune. The Indian Express, 4 August 2009. http://indianexpress.com/article/news-archive/web/first-indiah1n1-death-is-girl-in-pune/

8. Tandale BV, Pawar SD, Gurav YK, et al. Antibody persistence after Pandemic H1N1 2009 influenza vaccination among healthcare workers in Pune, India. Hum Vaccin Immunother 2013;9: 125-7.

9. Mishra AC, Chadha MS, Choudhary ML, et al. Pandemic influenza (H1N1) 2009 is associated with severe disease in India. PLOS ONE 2010;5:e10540.

10. Girard MP, Tam JS, Assossou OM, et al. The 2009 A (H1N1) influenza virus pandemic: a review. Vaccine 2010;28:4895-902.

11. Kwong EW, Pang SM, Choi PP, et al. Influenza vaccine preference and uptake among older people in nine countries. $J$ Adv Nurs 2010;66:2297-308.

12. Nagata JM, Hernandez-Ramos I, Kurup AS, et al. Social determinants of health and seasonal influenza vaccination in adults $\geq 65$ years: a systematic review of qualitative and quantitative data. BMC Public Health 2013;13:388.

13. Kumar S, Quinn SC. Existing health inequalities in India: informing preparedness planning for an influenza pandemic. Health Policy Plan 2012;27:516-26.

14. Primary Census Abstract, Census of India 2011. Government of India: Ministry of Home Affairs. http://www.censusindia.gov.in/pca/ default.aspx (accessed 10 Feb 2014).

15. John TJ, Moorthy M. 2009 pandemic influenza in India. Indian Pediatr 2010;47:25-31.

16. Kudale A, Purohit VS, Sundaram N, et al. Socioeconomic, cultural and behavioural features of prior and anticipated influenza vaccine uptake in urban and rural Pune district, India: a mixed-methods case study. BMJ Open 2013;3:e002573.

17. Weiss MG. Explanatory Model Interview Catalogue (EMIC): framework for comparative study of illness. Transcult Psychiatry 1997;34:235-63.

18. Weiss MG. Cultural epidemiology: an introduction and overview. Anthropol Med 2001;8:5-29.

19. Dupras $\mathrm{C}$, Williams-Jones $\mathrm{B}$. The expert and the lay public: reflections on influenza $\mathrm{A}(\mathrm{H} 1 \mathrm{~N} 1)$ and the risk society. Am J Public Health 2012;102:591-5.

20. Allam RR, Murhekar MV, Tadi GP, et al. Descriptive epidemiology of novel influenza A (H1N1), Andhra Pradesh 2009-2010. Indian J Public Health 2013:57:161-5.

21. Broor S, Sullender W, Fowler K, et al. Demographic shift of influenza $\mathrm{A}(\mathrm{H} 1 \mathrm{~N} 1)$ pdm09 during and after pandemic, rural India. Emerg Infect Dis 2012;18:1472-5.

22. Chadha MS, Hirve S, Dawood FS, et al. Burden of seasonal and pandemic influenza-associated hospitalization during and after 2009 $\mathrm{A}(\mathrm{H} 1 \mathrm{~N} 1)$ pdm09 pandemic in a rural community in India. PLoS ONE 2013;8:e55918.

23. Chudasama R, Patel U, Verma $P$, et al. A two wave analysis of hospitalizations and mortality from seasonal and pandemic 2009 A (H1N1) influenza in Saurashtra, India: 2009-2011. Ann Med Health Sci Res 2013;3:334-40.

24. Fowler KB, Gupta V, Sullender W, et al. Incidence of symptomatic A (H1N1)pdm09 influenza during the pandemic and post-pandemic periods in a rural Indian community. Int $J$ Infect Dis 2013;17: e1182-5.

25. Kamate SK, Agrawal A, Chaudhary $\mathrm{H}$, et al. Public knowledge, attitude and behavioural changes in an Indian population during the Influenza A (H1N1) outbreak. J Infect Dev Ctries 2010;4:7-14.

26. Chaudhary V, Singh RK, Agrawal VK, et al. Awareness, perception and myths towards swine flu in school children of Bareilly, Uttar Pradesh. Indian J Public Health 2010;54:161-4.

27. Chudasama RK, Patel UV, Verma PB, et al. Clinico-epidemiological features of the hospitalized patients with 2009 pandemic influenza A ( 1 1N1) virus infection in Saurashtra region, India (September, 2009 to February, 2010). Lung India 2011;28:11-6.

28. AYUSH interventions in the management of common flu like conditions. Government of India: Department of AYUSH-Ministry of Health \& Family Welfare. http://mohfw-h1n1.nic.in/documents/PDF/ ayush.pdf (accessed 20 Jan 2014).

29. World Health Organization. Pandemic influenza preparedness and response: a WHO guidance document. Geneva: WHO Press, 2009. http://whqlibdoc.who.int/publications/2009/9789241547680_eng.pdf? ua $=1$

30. Ferguson NM, Cummings DA, Fraser C, et al. Strategies for mitigating an influenza pandemic. Nature 2006;442: 448-52.

31. Bell D, Nicoll A, Fukuda K, et al. Non-pharmaceutical interventions for pandemic influenza, national and community measures. Emerg Infect Dis 2006;12:88-94. 
32. Brewer NT, Chapman GB, Gibbons FX, et al. Meta-analysis of the relationship between risk perception and health behavior: the example of vaccination. Health Psychol 2007;26: $136-45$.

33. Wong VW, Cowling BJ, Aiello AE. Hand hygiene and risk of influenza virus infections in the community: a systematic review and meta-analysis. Epidemiol Infect 2014;142:922-32.

34. Pandemic plan: Pandemic preparedness and response for managing novel Influenza A H1N1. Government of India: Ministry of Health \& Family Welfare. http://mohfw-h1n1.nic.in/documents/PDF/Strategic\% 20Approach.pdf (accessed 22 Apr 2014).

35. Pandemic influenza-A (H1N1): Do's and Don'ts for the Community. Government of India: Ministry of Health \& Family Welfare. http:// mohfw-h1n1.nic.in/documents/PDF/Annexure\%20XXIII.pdf (accessed 22 Apr 2014)

36. SteelFisher GK, Blendon RJ, Ward JR, et al. Public response to the 2009 influenza A H1N1 pandemic: a polling study in five countries. Lancet Infect Dis 2012;12:845-50.

37. Ramsey CD, Funk D, Miller RR, et al. Ventilator management for hypoxemic respiratory failure attributable to $\mathrm{H} 1 \mathrm{~N} 1$ novel swine origin influenza virus. Crit Care Med 2010;38:e58-65.

38. Uyeki T. Antiviral treatment for patients hospitalized with 2009 pandemic influenza A (H1N1). N Engl J Med 2009;361:e110.

39. Yu H, Liao Q, Yuan $Y$, et al. Effectiveness of oseltamivir on disease progression and viral RNA shedding in patients with mild pandemic 2009 influenza A H1N1: opportunistic retrospective study of medical charts in China. BMJ 2010;341:c4779.

40. Jefferson T, Jones MA, Doshi $\mathrm{P}$, et al. Neuraminidase inhibitors for preventing and treating influenza in healthy adults and children. Cochrane Database Syst Rev 2014;4:CD008965.
41. Saunders PJ, Middleton J. Current evidence shows no place for antiviral drug distribution in a flu pandemic. BMJ 2014;348:g2955.

42. John TJ, Muliyil J. Pandemic influenza exposes gaps in India's health system. Indian J Med Res 2009;130:101-4.

43. Barua N, Pandav CS. The allure of the private practitioner: is this the only alternative for the urban poor in India? Indian J Public Health 2011:55:107-14.

44. Ergler CR, Sakdapolrak P, Bohle HG, et al. Entitlements to health care: why is there a preference for private facilities among poorer residents of Chennai, India? Soc Sci Med 2011;72:327-37.

45. Kumar C, Prakash R. Public-private dichotomy in utilization of health care services in India. Consilience: J Sustainable Development 2011:5:25-52.

46. Byatnal A. Second wave of swine flu hits Pune. The Hindu, 30 July 2010. http://www.thehindu.com/news/national/ second-wave-of-swine-flu-hits-pune/article542400.ece

47. H1N1 in post-pandemic period. Director-General's opening statement at virtual press conference (10 August 2010). World Health Organization. http://www.who.int/mediacentre/news/statements/2010/ h1n1_vpc_20100810/en/ (accessed 20 Oct 2014).

48. Isalkar U. More deaths, cases of swine flu in 2013; virus still prevalent. The Times of India, Pune. 29 December 2013. http:// timesofindia.indiatimes.com/city/pune/More-deaths-cases-ofswine-flu-in-2013-virus-still-prevalent/articleshow/ $28067230 . \mathrm{cms}$

49. Isalkar U. Four swine flu patients critical. The Times of India, Pune. 20 August 2014. http://timesofindia.indiatimes.com/city/pune/Fourswine-flu-patients-critical/articleshow/40437983.cms

50. Galea S, Tracy M. Participation rates in epidemiologic studies. Ann Epidemiol 2007; 17:643-53. 